Indonesian Journal of Biotechnology, December, 2014

Vol. 19, No. 2, pp.146-152

\title{
The Susceptibility of katG Ser315Thr Mycobacterium tuberculosis mutant Against Anti Tuberculosis Drugs
}

\author{
Ning Rintiswati ${ }^{*}$, Praseno $^{1}$
}

${ }^{1}$ Department of Microbiology, Faculty of Medicine, Universitas Gajdah Mada, Yogyakarta, Indonesia

\begin{abstract}
Mycobacterium tuberculosis resistant strains is a matter of great concern for TB control Program since no cure for some multi drug resistance TB (MDR-TB) cases. These strains could spread around the world, make a great challenges for control measures. Mycobacterium tuberculosis strains resistance to anti tuberculosis drugs is mainly caused by the alteration in several genes encoding the molecular targets. Mutation of $k a t G$ at codon 315 especially Ser315Thr are responsible for INH resistance in a large proportion of TB cases. The aim of this study is to know the frequency of of katG Ser315Thr of $M$. tuberculosis mutant and the pattern of resistance to Anti TB drugs. The study design was observational laboratoric. Eighty five M. tuberculosis INH resistant clinical isolates were screened for mutation of katGSer315Thr by using PCR-RFLP and DNA sequence analysis.The results showed that $\mathrm{kat} G \mathrm{Ser} 315 \mathrm{Thr}$ were identified in $23(27,05 \%)$ of INH resistance isolates. Frequency of MDR among the katG Ser315Thr mutants almost double than the non mutant. The result suggested that the the $k a t G$ Ser315Thr mutation may play important role in the development of MDR-TB.
\end{abstract}

Keywords: katG Ser315Thr Mycobacterium tuberculosis mutant, frequency, anti TB drugs, Multi Drug Resistant, pattern of resistance.

\section{Introduction}

Despite the declaration of tuberculosis (TB) as a "global emergency" by the World Health Organization almost 20 years ago, TB still remain as a global problem in the world (Zhang et al.,2005). The latest estimates included in this report are that there were 9.0 million new TB cases in 2013 and 1.5 million TB deaths (WHO, 2014). The increased of HIV cases and low socioeconomic status greatly influenced the development of TB (Rattan et al., 1999; Dye, 2006). Another obstacle in overcoming TB problem is the emergence of M.tuberculosis mutant that is resistant to anti TB drugs. The emergence of resistant strain is caused by lengthy therapy of at least six months makes patient uncompliance, so have inadequate treatment, then induce

* Corresponding author:

Ning Rintiswati

Department of Microbiology, Faculty of Medicine, Universitas Gajdah Mada, Yogyakarta, Indonesia

Email : rintiswati@gmail.com changes in bacterial properties which in turn become resistant to anti TB drugs. The WHO reported the frequency of drug-resistant strains M.tuberculosis ranging from 3 to $41 \%$ among 72 countries. The current problems are the emerge of multi drug resistant TB (MDR-TB), which is resistant to isoniazid (INH) and rifampicin, and extreme drug resistant TB (XDR-TB). The XDRTB strain is MDR with additional resistant to one of fluoroquinolones, and one or more of injectable drugs, such as kanamycin, amikacin, and capreomycin. MDR-TB and XDR-TB caused several fatal outbreaks worldwide (WHO, 2009). INH is one of effective anti TB drugs with minimal inhibitory concentration (MIC) of $0.2-0.06 \mathrm{mg} / \mathrm{L}$, nevertheless the rate of resistance to this drug is increasing ( WHO \&IUATLD, 2004). INHpro-drug which is highly dependent on $\mathrm{Kat} G$ to become reactive radical that attack target in M.tuberculosis cell.

Until date, INH along with rifampicin are backbones of TB treatment. INH had been used as first line anti TB medicine since 
1952 to combat TB. There was a postulate stated that INH was an active pro drug after transforming by catalase peroxidase (KatG) became isonicotinate acid, and this change produced radicals that could interact with a main target within a mycobacterial cell (Musser, 1995; Heym et al.,1996; Bardou et al., 1998).

M.tuberculosis primary resistance towards INH emerged in the laboratory with estimated frequency of $10^{-5}-10^{-7}$ that was higher than rifampicin. It was known that M.tuberculosis resistance towards INH was mostly related with mutation that involved 1 or 2 genes namely katG, inhA and $a h p C$ (Heym et al., 1997; Talenti et al., 1997; Morlock et al., 2003).

kat $G$ encodes catalase peroxide enzyme (KatG). This enzyme had a multiple function as a catalase and peroxidase with a wide specification. Along with a catalyst reaction and enzyme peroxide, it functioned to free peroxide hydrogen from a biological system to protect bacterial cells from damages by reactive peroxides that produced by macrophage. Peroxidase has important roles in INH activation.

It was reported that $20-80 \%$ of INH resistant $M$.tuberculosis associated with $\mathrm{kat} G$ mutation, and the frequency was related to geographical region of clinical isolate origin. Among katG mutation, Ser315Thr mutation contributes to $50-93 \%$ of INH resistant M. tuberculosis clinical isolates (Zhang et al.,2005).

Mutation of katG is the main resistance mechanism of INH, and mutation on codon 315 (Ser315Thr) is the most frequently documented. This mutation responsible to the increasing of MIC as of 200 times compared to that of $\mathrm{H} 37 \mathrm{Rv}$ M.tuberculosis. This mutation is strongly associated with MDR mutant and transmitted easily among M. tuberculosis strain. Mutation may result in decrease activity of catalase-peroxidase and deletion of this gene may cause loss of the enzyme activity (Mokrousov, 2002; Xueqiong et al., 2006; Hu et al., 2010).
It is important to analyze the pattern of resistance of katG Ser315Thr M.tuberculosis mutant to first line anti TB drugs. This study aimed to describe the pattern of anti TB drugs resistant among katG Ser315Thr M.tuberculosis mutant.

\section{Material and Methods \\ M. tuberculosis isolates.}

M. tuberculosis clinical isolates are archive strains of Microbiology Laboratory, Faculty of Medicine, Universitas Gadjah Mada. M.tuberculosis were cultured, identified, and continued by kat $G$ mutation detection. kat $G$ Ser315Thr mutant of M.tuberculosis were tested for its sensitivity towards anti TB drugs.

\section{M. tuberculosis identification.}

M.tuberculosis were cultured on Lowenstein Jensen (LJ) medium, and incubated at $37^{\circ} \mathrm{C}$ for 3-4 weeks, with weekly observation. M. tuberculosis was identified based on the colony morphology, Ziehl Nielsen staining, Niacin test and PNB test. M.tuberculosis on LJ medium developed a creamy colored colony with dry and rough consistence, grew slowly, did not grow on PNB supplemented LJ Medium, and positively reacted to Niacin.(Vestal, 1981)

\section{Antimicrobial susceptibility test.}

Antimicrobial susceptibility test was performed by using modified indirect proportional on LJ medium. Each sample was cultured on a series of LJ medium containing first line anti tuberculosis drugs; Streptomycin $(4 \mathrm{mg} / \mathrm{L}), \mathrm{INH}(0.2 \mathrm{mg} / \mathrm{L}$ and $1.0 \mathrm{mg} / \mathrm{L})$, Ethambutol $(2 \mathrm{mg} / \mathrm{L})$, and Rifampicin (40 mg/L). Specimen was also cultured on LJ medium without drug and served as control. Inoculated media were incubated at $37 \mathrm{C}$ for 3 weeks. Confluent growth on control was considered as $100 \%$ growth. Sensitive or resistant determination was based on comparison between growth on medium with and without drug. An strain was considered resistant if the colonies 
reach $1 \%$ of colony count on control medium (Vestal, 1981).

\section{DNA isolation}

M. tuberculosis DNA isolation was carried out with boiling method according to Herrera et al. (2004). M. tuberculosis were scrapped from LJ and placed in tube containing $500 \mu \mathrm{L}$ of sterile aquadest and heated at $95 \mathrm{C}$ for 5 minutes. Samples were then spinned at $12.000 \mathrm{X} \mathrm{g}$ for 5 minutes, supernatants were saved and used as DNA template.

\section{Mutation analysis of $\mathrm{katG}$ Ser315Thr (AGC $>$ ACC)}

Mutation detection was performed by using PCR-RFLP method. One set of primers katG IF (5'AGCTCGTATGGCACCGGAAC) and katG 4R (5'-AACGGGTCCGGGATGGTG-3') were used for $k a t G$ fragment amplification (position 904 to 1103 in H37Rv) (Mokrousov, 2002). Amplified fragments were digested with MspI. Briefly, $15 \mu \mathrm{L}$ PCR product was added with $10 \mu \mathrm{L}$ of buffer and $2.7 \mu \mathrm{L}$ of the enzyme. The mixtures were incubated in waterbath at $37^{\circ} \mathrm{C}$ for $8-16$ hours. Digested fragments and marker $\mathrm{V}$ (Roche) were subjected to $4 \%$ agarose gel electrophoresis and results were visualized with UV light. Mutated codon 315 will be digested by MspI, resulting in 7 fragments ; 14, 6, 21, 6, 11, 10, and 132 bps. Digestion of non mutant katG Ser315Thr resulted in 6 fragments; $14,6,6,11,10$, and 153 bps (adapted from Mokrousov et al., 2002). The PCR-RFLP analysis was confirmed with DNA sequencing analysis.

\section{Results and Discussion \\ Ser315Thr mutant of M.tuberculosis isolates}

In this study 85 INH-resistant M.tuberculosis isolates were obtained. Ten INH-sensitive isolates, which were culture collection from Laboratory of Microbiology, Faculty of Medicine Gadjah Mada university, were also included in the study. PCRRFLP procedures were performed for 85 M. tuberculosis clinical isolates. The representative electrophoresis of PCR-RFLP procedure was showed in Figure 1.

DNA sequence analysis was performed to confirm the PCR-RFLP results for randomly selected eight $M$. tuberculosis isolates (7 mutants and 1 standard strain of H37Rv) (Fig 2).

Overall mutation on katG Ser315Thr of M.tuberculosis among INH resistant

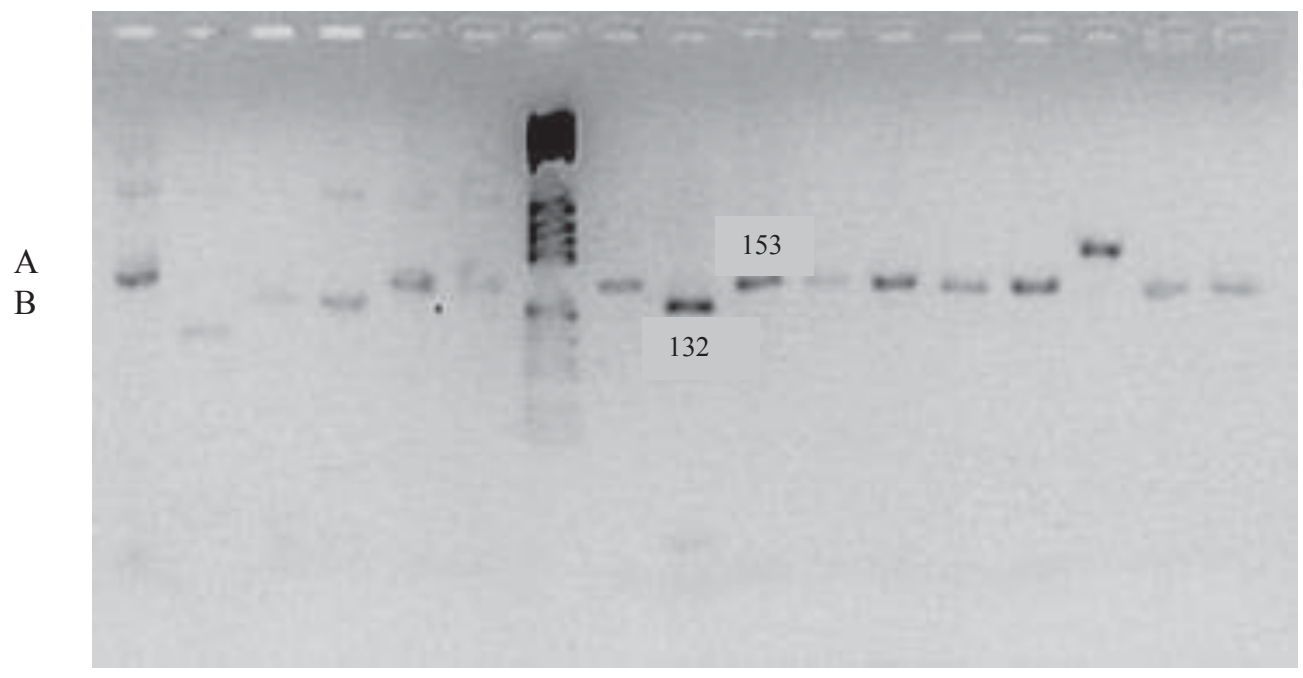

Figure 1. PCR-RFLP analysis result. PCR amplification of katG gene segment produced 199 bp bands. PCR products were digested by using MspI restriction ezyme. After digestion, mutant katG Ser315 Thr produced 132bp fragment while non mutant produced 153bp fragment. 
A

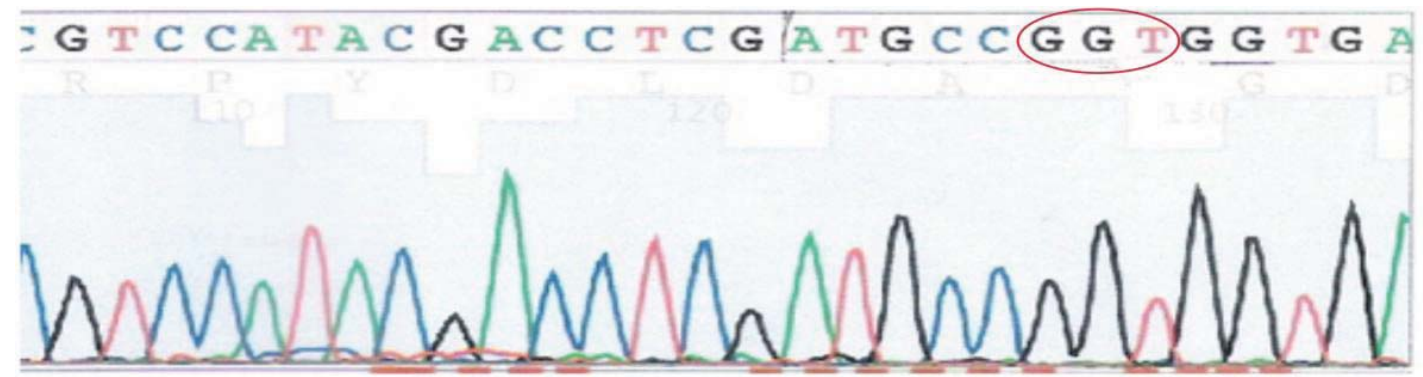

B
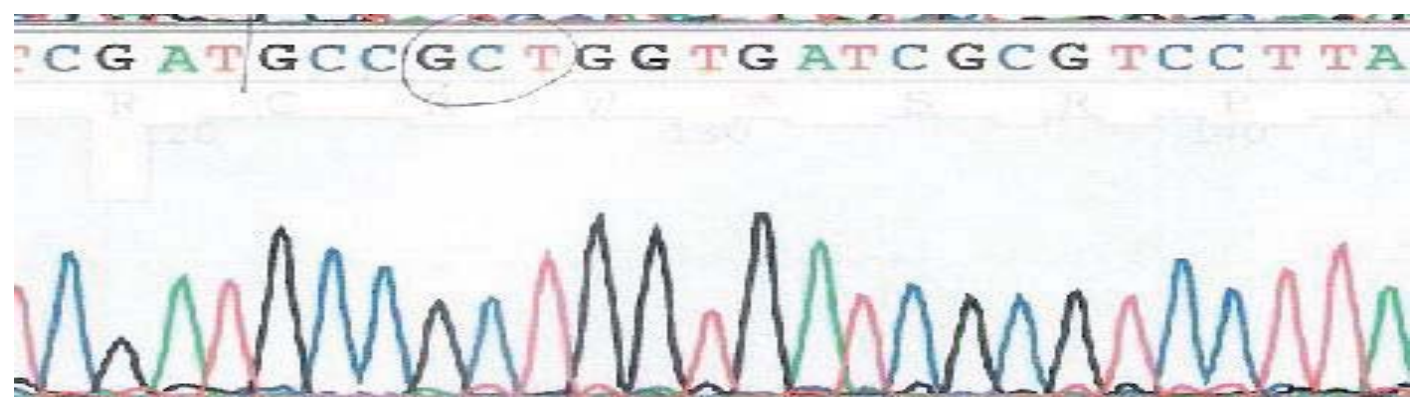

Figure 2. DNA Sequencing result of codon $315 \mathrm{katG}$ M.tuberculosis (reverse primer ) A : DNA fragment of representative mutant $M$. tuberculosis with ACC at codon 315, B : DNA fragment of H37Rv strain at the same position showed AGC

Table 1. The Frequency of katG Ser315Thr M.tuberculosis mutant among the samples and the resistency to INH

\begin{tabular}{|c|c|c|c|c|}
\hline M. tuberculosis & Resistant to INH & Sensitive to INH & No & $\begin{array}{c}\text { Sensitivity, Specificity PPV, } \\
\text { NPV (\%) }\end{array}$ \\
\hline Mutant & $23(27,06 \%)$ & $0(0 \%)$ & 23 & $\begin{array}{l}\text { Sensitivity : } 27,05 \\
\text { Specificity : } 100,0\end{array}$ \\
\hline Non mutant & $62(72,94 \%)$ & $10(100 \%)$ & 72 & $: 100,0$ \\
\hline Total & $85(100,00 \%)$ & $10(100 \%)$ & 95 & $: 13,88$ \\
\hline
\end{tabular}

PPV= Positive Predictive Value, NPV =Negative Predictive Value

strain were relatively low $(27,05 \%)$. It was reported that mutation on katG 315 codon in $M$. tuberculosis clinical isolates was most frequently found (50\%-90\%), the remaining mutations occurred in other loci (Musser, 1995; van Solingen et al., 2000; Mokrousov et al., 2004) It was suggested that mutation in this codon is beneficial for the bacteria, since it can reduce INH activity without removing catalase peroxidase activity that serve as virulance factor.

The results indicated that mutation katG315T may responsible for the phenotypic of INH resistance in index strains. The mutation only occur in INH resistant isolates, but not in INH sensitive isolates.

\section{Susceptibility of katGSer315Thr mutants to anti TB drugs}

Table 2 showed that the highest proportion of resistance in katGSer315Thr mutant was to three drugs (INH, rifampicin, and streptomycin). In non mutant isolates the highest frequency found was single drug resistance against INH. Among 23 mutant isolates, $14(60.1 \%)$ isolates were resistant 
Table 2. Susceptibility of katG Ser315Thr M.tuberculosis mutant and non mutant against anti tuberculosis drugs.

\begin{tabular}{l|c|ccc|c|c|c|c|}
\hline \multirow{2}{*}{\multicolumn{1}{c}{ M. tuberculosis }} & \multirow{2}{*}{$\mathrm{n}$} & \multicolumn{6}{c}{ Resistant to Anti Tuberculosis Drugs } \\
\cline { 3 - 9 } \multicolumn{1}{c|}{} & & $\mathrm{I}$ & $\mathrm{I}+\mathrm{R}$ & $\mathrm{I}+\mathrm{E}$ & $\mathrm{I}+\mathrm{R}+\mathrm{S}$ & $\mathrm{I}+\mathrm{S}+\mathrm{E}$ & \multicolumn{1}{c}{$\mathrm{I}+\mathrm{R}+\mathrm{S}+\mathrm{E}$} \\
\hline katG Ser315Thr Non mutant & 62 & 30 & 13 & 13 & 5 & 0 & 1 \\
\hline katG Ser315Thr Mutant & 23 & 4 & 4 & 4 & 10 & 1 & 0 \\
\hline
\end{tabular}

Note: I; INH R: rifampicin; S: streptomycin; E: ethambutol

Table. 3 Susceptibility of katG Ser315Thr mutant and katG Ser315Thr non mutant against INH

\begin{tabular}{lccc}
\hline \multicolumn{1}{c}{ M. tuberculosis } & $\mathrm{n}$ & $\begin{array}{c}\text { Resistant to more than one } \\
\text { drug }(\%)\end{array}$ & Resistant toINH (\%) \\
\hline katG Ser315Thr non mutant & 62 & $32(51.61)$ & $30(48.39)$ \\
katG Ser315Thr mutant & 23 & $19(82.61)$ & $4(17.40)$ \\
\hline
\end{tabular}

to at least INH and rifampin, which was categorized as MDR isolates. Of 62 non mutant isolates, 19 (36.5\%) were MDR (data not shown).

Table 2 and 3 showed the difference of single drug resistant frequency among katG Ser315Thr mutant and non mutant. katG Ser315Thr mutant tend to resistant against more than 1 anti tuberculo sis drugs. It was noted that in the mutant group the MDR-TB (at least resistant against INH and Rifampicin) frequency is higher $(60.85 \%)$ compare to $31.6 \%$ in the non mutant group.

The katG Ser315Thr mutant $M$. tuberculosis predominantly resistant against 3 fist line drugs, while katG Ser315Thr non mutant $M$. tuberculosis predominantly resisntant against single drugs (INH). This observation was in accordance to the previous report, $60.1 \%$ of katG Ser315Thr mutant were MDR-TB, whereas only $36.5 \%$ MDR-TB were reported in non mutant (Hasbon et al., 2006).

There are two hypothetical theories concerning the association between mutation on katG and INH resistant mechanism. Mutation on katG315 plays important role in the emergence of secondary resistance after development of primary resistance. Mutation on katG occurs after the isolates become MDR. The other hypothesis stated that mutation on katG315 causes isolates become more resistant, more easily transmissible, and develop to MDR (Zhang et al., 2005).
Hazbon suggested that resistance to INH and evolution of MDR strains is very complex and dynamic, involving various genes interaction and anti $\mathrm{TB}$ drug resistace phenotype ( Hazbon et al.,2006; Bulatovic et al., 2002; Van Solingen et al., 2000). More extensive studies are needed to be able to explain mechanism of resistance to anti TB drugs. It is also important to develop new molecular-based diagnostic method (Zhang et al., 2005).

Resistance to INH has been associated with deletion or point mutation on katG gene in which serine is replaced with threonin at position 315 (Ser315Thr). Substitution of ser-315 is one of the most frequent mode in clinical isolates with resistance to INH (Van Solingen et al., 2000; Luo et al., 2010; Jagielski et al., 2013). Minimal inhibitory concentration of INH resistant isolates increase 20-200 times. With position of cytochrome oxidase super family peroxidase-catalase, it is suggested that Ser315 is close to active site of KatG so that Ser315Thr mutation influence enzyme activity of KatG (Heym et al., 1998; Bulatovic et al., 2002; Van Solingen et al., 2000.; Luo et al., 2013).

Our results showed that $k a t G S e r 315 T h r$ mutation was frequently $(27.06 \%)$ found in the INH resistant $M$. tuberculosis that may responsible for the multi resistant against anti tuberculosis drugs. 


\section{References}

Bardou, F., Raynaud, C., Ramos, C., Laneelle, M.A., Laneelle, G., 1998. Mechanism of isoniazid uptake in M.tuberculosis. Microbiology .144: 2539-2544.

Bulatovic, V.M., Wangenack, N.L., Uhl, J.R., Halal,L., Roberts, G.D,Cockerill III, F.R., Rusnack,F., 2002. Oxidative stress increases susceptibility of M.tuberculosis to Isoniazid. Antimicrob. Agent Chemother, 46(9): 2765-2771.

Dye, C., 2006. Global epidemiology of tuberculosis. Lancet 367: 938-40.

Hazbon, M.H., Brimacombe, M., del Valle, M.B., Cavatore, M., Guerrero, M.I., Varma-Basil, M., et al., 2006 . Population Genetic Study of Isoniazid Resistance Mutation and Evolution of MultidrugResistant Mycobacterium tuberculosis. Antimicrob. Agent Chemother. 50 (8):26402649.

Herrera, L., Valverde, A., Saiz, P., Saez-Nieto, J.A., Portero, J.L., Jimenez, M.S., 2004. Molecular characterization of isoniazidresistant M.tuberculosis clinical strains isolated in Philippines. Intern J.of Antimicrob. Agents. 23: 572-576.

Heym, B., Philipp, W., Cole, S.T., 1996. Mechanism of drug resistance in Mycobacterium tuberculosis. Dalam Shinnick,T.M (ed.), Tuberculosis, Curr in Microb and Immunol.Springer:49-70.

$\mathrm{Hu}$, Y., Hoffner, S., Jiang, W., Wang,W., $\mathrm{Xu}, \mathrm{B} ., 2010$. Extensive transmission of isoniazid resistant M.tuberculosis and its association with increased multidrug-resistant TB in two rural counties of eastern China: A molecular epidemiological study. BMC infect. dis. 10(43).1471-2334.

Jagielski T, Grzeszczuk M, Kamiński M, Roeske K, Napiórkowska A, Stachowiak R, Augustynowicz-Kopeć E, Zwolska Z, Bielecki J. 2013. Identification and analysis of mutations in the $\mathrm{katG}$ gene in multidrug-resistant Mycobacterium tuberculosis clinical isolates.Pneumonol Alergol Pol. 2;81(4):298-307.
Luo, T., Zhao, M., Li, X., Xu, A.P., Gui, X., Pickerill, S., DeRiemer, K., Mei J., and Gao, Q., 2010. Selection of Mutations To Detect Multidrug-Resistant Mycobacterium tuberculosis Strains in Shanghai, China Antimicrob Agent Chemother, 54 (3), . 2010:. 1075-1081

Mokrousov, I., Otten, T., Filipenko, M., Vyazovaya, A., Chrapov, E., Limeschenko, E., Steklova, L., Vyshnevskiy, B., Narvskaya, O., 2002. Detection of isoniazid -resistant M.tuberculosis strain by a multiplex allele-specific PCR assay targeting katG codon 315 variation. J. Clin. Microbiol, 46(5): 2509-2512.

Morlock, G.P., Metchock, B., Sikes D, Craford JT, Cooksey RC., 2003. ethA, inhA and $\mathrm{kat} G$ loci of ethionamide resistant clinical M.tuberculosis isolates. Antimicrob. Agent Chemother. 47(12): 3799-3805.

Musser, J.M., 1995. Antimicrobial agent resistance in Mycobacteria: molecular genetic insight. Clin. Microb. Rev., 8 (4) : 496-514.

Rattan,A., Kalia, A., Ahmad, N., 1999. Multidrug resistant Mycobacterium tuberculosis molecular respectives. Ind.J. Tub. 46:51-63.

Talenti, A., Honore, N., Bernasconi, B., , J, Ortega,A., Heyan, B., Takiff, H.E., and Cole, S.T., 1997.Genotypic assessment of isoniazid and rifampin resistance in M.tuberculosis: A blind study at reference lab level. J. Clin. Microbiol, 35(3)::719-723

van Solingen, D., de Haas, P., van Doorn, H.R., Kuijper, E., Rinder, H., Borgdorff, M.W., 2000. Mutation at amino acid potition 315 of the kat $\mathrm{G}$ gene are associated with high-level resistance to isoniazid, other drug resistance in The Netherlands. J. Infect Dis. 182: 1788-90.

Vestal AL. ,1981.Procedures for Isolation and Identification of Mycobacterium. Center for Disease Control.US. Dep. of health and human services, Atlanta, Georgia. 
World Health Organization, 2014 Global Tuberculosis Report 2014. WHO, 10-13

World Health Organization \& IUATLD. 2004. Anti Tuberculosis in the World. Report no.3.The WHO/IUATLD Global Project on Anti-TB drug Resistance Surveillance 1999-2002 WHO :11-12.

Xue-qiong, W., Yang, L., Jun-xian, Z., Jianqin, L., Hong- Min, L., Guang- Yu, Z., Cui- Huan, L., Bei-Chuan, D., 2006. Detection of mutant katG 315 \& Inh A-15 of Mycobacterium tuberculosis strain isolates from Chinese patients. Clin. Med. J. 119(3): 230-233.

Zhang, Y., Vilcheze, C., Jacobs, W.R., 2005. Mechanisms of Drug Resistance in Mycobacterium tuberculosis. Dalam Cole, S.T. Tuberculosis and tubercle bacillus. ASM Press, Washington DC. 115-132. 